\title{
Sindrome do impacto posterior do tornozelo: um diagnóstico que deve ser lembrado pelo Reumatologista. Relato de dois casos
}

\author{
Adriano Chiereghin ${ }^{1}$, Michele Rodrigues Martins ${ }^{1}$, Carina Mori Frade Gomes ${ }^{2}$, \\ Renata Ferreira Rosa ${ }^{3}$, Sonia Maria Alvarenga Anti Loduca ${ }^{4}$, Wiliam Habib Chahade ${ }^{5}$
}

\begin{abstract}
RESUMO
O tornozelo é sítio frequente de sintomas dolorosos em atletas e não atletas. A dor localizada na região posterior pode ser o resultado final de diversas patologias, sendo um desafio diagnóstico para o reumatologista. A síndrome do impacto (pinçamento) posterior do tornozelo, também denominada síndrome os trigonum e síndrome compressiva tibiotalar posterior, é um distúrbio clínico caracterizado por dor aguda ou crônica na região posterior do tornozelo, desencadeada pela flexão plantar forçada, que promove microtrauma crônico repetitivo. A patologia do processo os trigonum-talar é a causa mais comum dessa síndrome, mas existem outras causas, como tenossinovite do flexor longo do hálux, osteocondrite de tornozelo, doença da articulação subtalar e fratura. O diagnóstico baseia-se na história clínica e exame físico, e complementado por achados na radiografia simples (RX), ultrassom (US), cintilografia, tomografia computadorizada (TC) e ressonância magnética (RM). Destacamos o RX por seu baixo custo e boa sensibilidade, o US pela possibilidade de guiar infiltrações terapêuticas e a RM pela possibilidade de avaliar partes moles adjacentes.
\end{abstract}

Palavras-chave: tornozelo, traumatismos do tornozelo, articulação do tornozelo.

[Rev Bras Reumatol 2011;51(3):283-8] CElsevier Editora Ltda

\section{INTRODUÇÃO}

Dor no tornozelo é queixa frequente nos ambulatórios e consultórios dos reumatologistas, porém, o diagnóstico de síndrome do impacto posterior do tornozelo é pouco lembrado na prática médica diária. Relatamos dois casos em que, após avaliação clínica e radiológica adequada, definiu-se o diagnóstico como síndrome do impacto posterior do tornozelo, sendo possível instituir terapêutica adequada e obter resposta satisfatória. Ressaltamos a importância da história clínica e ocupacional para alertar o diagnóstico.

\section{RELATO DE 2 CASOS}

\section{Caso 1}

$\mathrm{JN}$, sexo masculino, 46 anos, motorista, apresentava queixa de dor em face plantar do calcanhar esquerdo havia 6 anos, que piorava ao dirigir. Ao exame apresentava dor na flexão de pé esquerdo. A RM evidenciou presença de ossículo trigonal acessório associado à artropatia subtalar posterior e processo inflamatório adjacente. Foi orientado uso de AINH com melhora total da queixa (Figura 1).

\section{Caso 2}

MA, sexo feminino, 61 anos, professora, apresentava queixa de dor em calcanhares e face posterior de tornozelos, principalmente à esquerda, havia 2 anos, com piora à deambulação e ao ficar muito tempo em pé. Ao exame apresentava dor na flexão forçada dos pés. RX simples da região evidenciou presença de os trigonum. Foi orientado repouso e introduzido anti-inflamatório não hormonal com boa resposta (Figura 2).

\section{DISCUSSÃO}

A síndrome do impacto posterior é uma condição que surge da compressão dos tecidos moles entre o processo posterior

Recebido em 15/4/2010. Aprovado, após revisão, em 18/1/2011. Os autores declaram a inexistência de conflitos de interesse.

Hospital do Servidor Público Estadual Francisco Morato de Oliveira HSPE-FMO.

1. Aluno De especialização em Reumatologia; Especialista em Clínica Médica, HSPE-FMO

2. Médica-reumatologista; Especialista em Reumatologia pela SBR

3. Mestre em Reumatologia pelo HSPE-FMO; Assistente de Reumatologia da Faculdade de Medicina do ABC (FMABC) e do Serviço de Reumatologia do HSPE

4. Auxiliar de Ensino da Disciplina de Reumatologia da FMABC; Médica-assistente e Preceptora do Serviço de Reumatologia do HSPE-FMO

5. Doutor em Reumatologia pela Universidade de São Paulo; Diretor do Serviço de Reumatologia do HSPE- FMO

Correspondência para: Rua Pedro de Toledo, 1.800. Vila Clementino, São Paulo, SP, Brasil. CEP: 04039-901. E-mail: dichi78@hotmail.com 


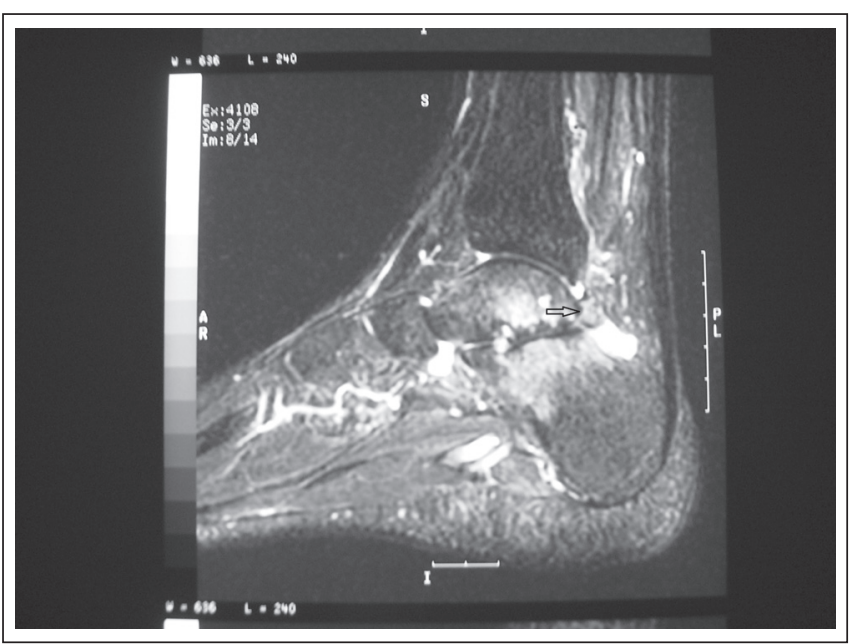

\section{Figura 1}

RM de tornozelo pós-gadolínio mostrando os trigonum e processo inflamatório associado.

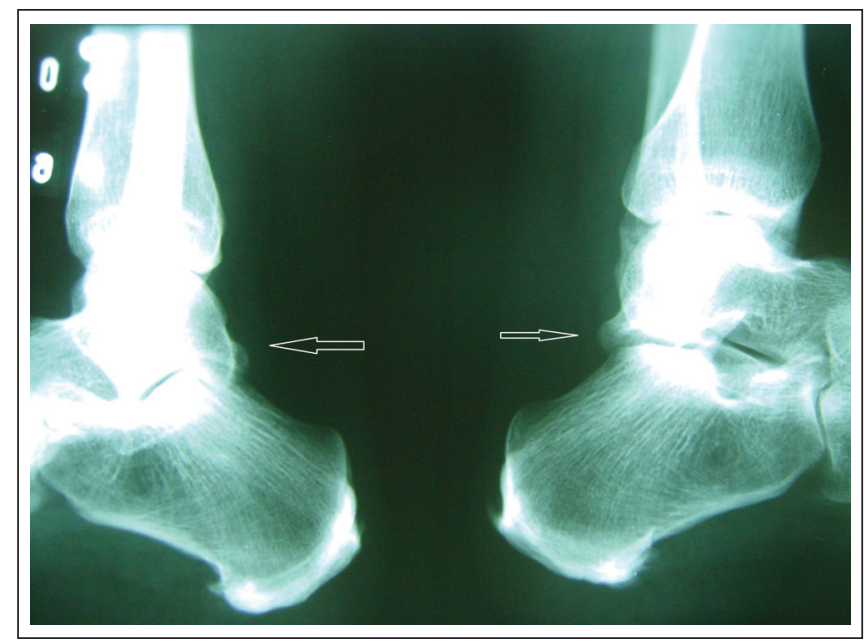

Figura 2

RX simples em incidência lateral mostrando os trigonum bilateral.

do calcâneo e tíbia posterior durante flexão plantar do tornozelo. ${ }^{5} \mathrm{Um}$ processo posterolateral do tálus (Stieda) proeminente pode ser uma importante causa da síndrome ou, se o os trigonum estiver presente, devido ao impacto com as estruturas adjacentes. ${ }^{6}$

O os trigonum é um centro de ossificação secundário no aspecto posterolateral do tálus e está presente em cerca de $5 \%$ a - 15\% dos pés "normais". A sua ossificação ocorre entre os 7 e 13 anos de idade, funde-se em 1 ano formando o processo Stieda, porém pode permanecer como um ossículo separado em $7 \%$ a $14 \%$ dos pacientes, geralmente de modo bilateral. ${ }^{6}$
Uma das causas de dor na região posterior do tornozelo na flexão plantar forçada é a lesão aguda na flexão plantar, levando à fratura do processo trigonal e a danos na sincondrose trigonal. Fratura crônica também pode ocorrer como resultado de estresse repetitivo. No entanto, o os trigonum pode ser sintomático mesmo permanecendo intacto durante a flexão plantar extrema.

O diagnóstico baseia-se primeiramente na história clínica e no exame físico dos pacientes que apontam incapacidade para as atividades em flexão plantar do tornozelo, tais como chute e apoio na ponta dos pés. Vale lembrar que são mais propensos ao desenvolvimento da patologia atletas que realizam esportes com chutes, bailarinas que usam a posição digitígrada, e trabalhadores que acionam pedais, como motoristas e costureiras. ${ }^{7}$ Ao exame físico, a palpação da porção posterior da articulação do tornozelo provoca dor, assim como a manobra de flexão plantar máxima passiva.

O achado radiográfico na incidência em perfil mostra o tubérculo posterior aumentado (processo de Stieda) ou presença do os trigonum; porém esses sinais nem sempre são a razão dos sintomas. O RX mostra o os trigonum e a calcificação secundária das ênteses que, na maioria das vezes, ocorre de maneira concomitante. Já a RM demonstra o processo inflamatório ocasionado pelo impacto posterior do os trigonum com a borda tibial, visíveis como imagem de alta intensidade intraóssea (edema ósseo) e na gordura periarticular. ${ }^{4}$

\section{Diagnóstico diferencial}

Nos casos de dor na região do tornozelo, é importante que o examinador clínico leve em consideração, com base no tipo de dor, a região atingida e a história clínica, uma série de diagnósticos para melhores condução e resolução do problema. Entre os diagnósticos possíveis, citamos os de maior relevância na Tabela $1 .$.

\section{Tabela 1}

Diagnósticos diferenciais em dor no tornozelo ${ }^{8}$

\begin{tabular}{ll}
\hline $\begin{array}{l}\text { Dor na região } \\
\text { posterior do tornozelo }\end{array}$ & $\begin{array}{l}\text { Dor na região medial } \\
\text { do tornozelo }\end{array}$ \\
\hline $\begin{array}{l}\text { Fratura de Shepherd's } \\
\text { (Fratura do tubérculo lateral da tíbia) }\end{array}$ & $\begin{array}{l}\text { Tendinite do flexor } \\
\text { longo do hálux }\end{array}$ \\
\hline Tendinite do flexor longo do hálux & Entorse do ligamento deltoide \\
\hline Tendinite do peroneal & Síndrome de Soleus \\
\hline Coalisão talocalcânea posterior & Tendinite do tibial posterior \\
\hline Pseudomenisco posterior & \\
\hline Osteoma osteoide do tálus posterior & \\
\hline
\end{tabular}




\section{Tratamento}

Deve ser conduzido de forma clínica com a orientação de repouso, fisioterapia, crioterapia, anti-inflamatório não hormonal ou hormonal por 4 a 6 semanas com um sucesso de aproximadamente $60 \% .{ }^{6}$ Existe ainda a possibilidade de tratamento cirúrgico quando há falha no seguimento clínico, fratura do processo trigonal, lesão osteocondral ou necessidade de reparo em estruturas neurovasculares. $\mathrm{O}$ procedimento cirúrgico ocorre com incisão aberta posteromedial ou posterolateral e tem uma taxa de sucesso de aproximadamente $75 \%$ com retorno a atividades em 3 a 5 meses; quando se opta por técnica artroscópica a taxa de complicação é de $1 \%$ a $9 \%$ menor, e o retorno às atividades ocorre em 9 semanas., ${ }^{4,9}$

\section{CONCLUSÃO}

A dor na face posterior do tornozelo é uma queixa comum. A síndrome do os trigonum é um dos diagnósticos diferenciais nos atletas, devendo também ser lembrada pelos reumatologistas na prática diária, mesmo em pacientes não atletas, especialmente se submetidos a estresse repetitivo na região posterior do tornozelo. $\mathrm{O}$ tratamento deve ser dirigido para a causa específica, sendo que, na maioria das vezes, os sintomas se resolvem com repouso e anti-inflamatórios. Em alguns casos, pode ser necessária intervenção cirúrgica.

\section{REFERENCES}

\section{REFERENNCIAS}

1. Bureau NJ, Cardinal E, Hobden R, Aubin B. Posterior ankle impingement syndrome: imaging findings in seven patients. Radiology 2000; 215(2):497-503.

2. Karasick D, Schweitzer ME. The os trigonum syndrome: imaging features. American Journal of Radiology 1996; 166:125-9.

3. Robinson P. Impingement syndrome of the ankle, European Radiology 2007; 17(12):3056-65.

4. Lima CMAO, Ribeiro E, Coutinho EPD, Vianna EM, Domingues RC, Junior ACC. Síndrome do impacto do tornozelo na ressonância magnética: ensaio iconográfico/Magnetic resonance imaging of ankle impingement syndrome: iconographic essay, Radiologia Brasileira 2010; 43(1):53-7.

5. Robison P, White LM. Soft-tissue and osseous impingement syndrome of the ankle: role of imaging in diagnosis and management. RadioGraphics 2002; 22(6):1457-71.

6. Maquirriain J. Posterior ankle impingement syndrome. Journal of American Academy of Orthopaedic Surgeons 2005; 13(6):365-71.

7. Hebert S, Xavier R, Pardini AG, Barros TEP et al. Ortopedia e traumatologia: princípios e prática, $3 \underline{a}$ edição. Porto Alegre: Artmed; 2009.

8. Hamilton WG. Posterior ankle pain in dancers. Clinics in sport medicine 2008; 27:263-77.

9. Lee JC, Calder JDF, Healy JC. Posterior impingement syndrome of the ankle. Seminars in Musculoskeletal Radiology 2008; 12(2):154-69. 